\title{
TRILHAS E TRAVESSIAS COMO FERRAMENTA PARA A CONSERVAÇÃO EM UCS: A EXPERIÊNCIA EM LAPINHA X TABULEIRO, MG
}

\author{
Lucas de Lima Fernandes Padoan ${ }^{1}$
}

\section{Resumo}

Trilhas e travessias são usualmente utilizadas como uma forma de estabelecer uma conexão com o meio natural em si, ligação esta que trocamos há muitos anos por grandes centros urbanos. Desse modo, colocamos em foco a travessia Lapinha x Tabuleiro, inserida na APA Morro da Pedreira, como importante ferramenta para a conservação, uma vez que se faz necessário a contraposição ao avanço indiscriminado dos processos de urbanização e do turismo predatório. Assim, corroboramos aqui com a importância ambiental da Serra do Espinhaço, bem como evidenciamos uma heterogeneidade de unidades paisagísticas perpassadas ao longo de um cruzamento da Serra do Espinhaço, sentido oeste para leste. Contudo, a necessidade de conservação não se faz exclusivamente pelas características fisiográficas da região, mas também pela inclusão de uma dinâmica social da população local inserida nesse espaço.

Palavras-chave: Travessia; Conservação; Biodiversidade.

\begin{abstract}
Trails and crossings are usually use as a way to establish a connection with the natural environment itself, this connection we exchanged many years ago by large urban centers. Thus, we put into focus the crossing Lapinha x Tabuleiro, located in APA Morro da Pedreira, as an important tool for conservation, since it is necessary to contrast the indiscriminate advancement of urbanization processes and the predatory tourism. Therefore, here we agree with the environmental importance of the Espinhaço, as the heterogeneity of landscape units pervaded over a cross from the Serra do Espinhaço, west to east direction. However, the need to preserve isn't made exclusively by physiographics characteristics of the region, but also by the inclusion of a social dynamic of the local population inserted in this space.
\end{abstract}

Keywords: Crossing; Conservation; Biodiversity.

\section{Introdução}

Trilhas e travessias são usualmente utilizadas como forma de estabelecer uma conexão com o meio natural, ligação esta que trocamos há muitos anos por grandes centros urbanos e, eventualmente, fugimos dessas grandes cidades em que habitamos para experimentar novas vivências com a natureza.

\footnotetext{
${ }^{1}$ Graduando em Ciências Socioambientais pela Universidade Federal de Minas Gerais.

E-mail: 1padoan2@ hotmail.com
} 
É nesse sentido que se insere a travessia denominada Lapinha $\mathrm{x}$ Tabuleiro, iniciada no pequeno vilarejo de Lapinha, próximo à Santana do Riacho, e finalizada em Tabuleiro, distrito de Conceição do Mato Dentro, trajeto localizado dentro da APA Morro da Pedreira (figura 1).

Figura 1. Transecto Santana do Riacho - Tabuleiro inserida na APA Morro da Pedreira/MG

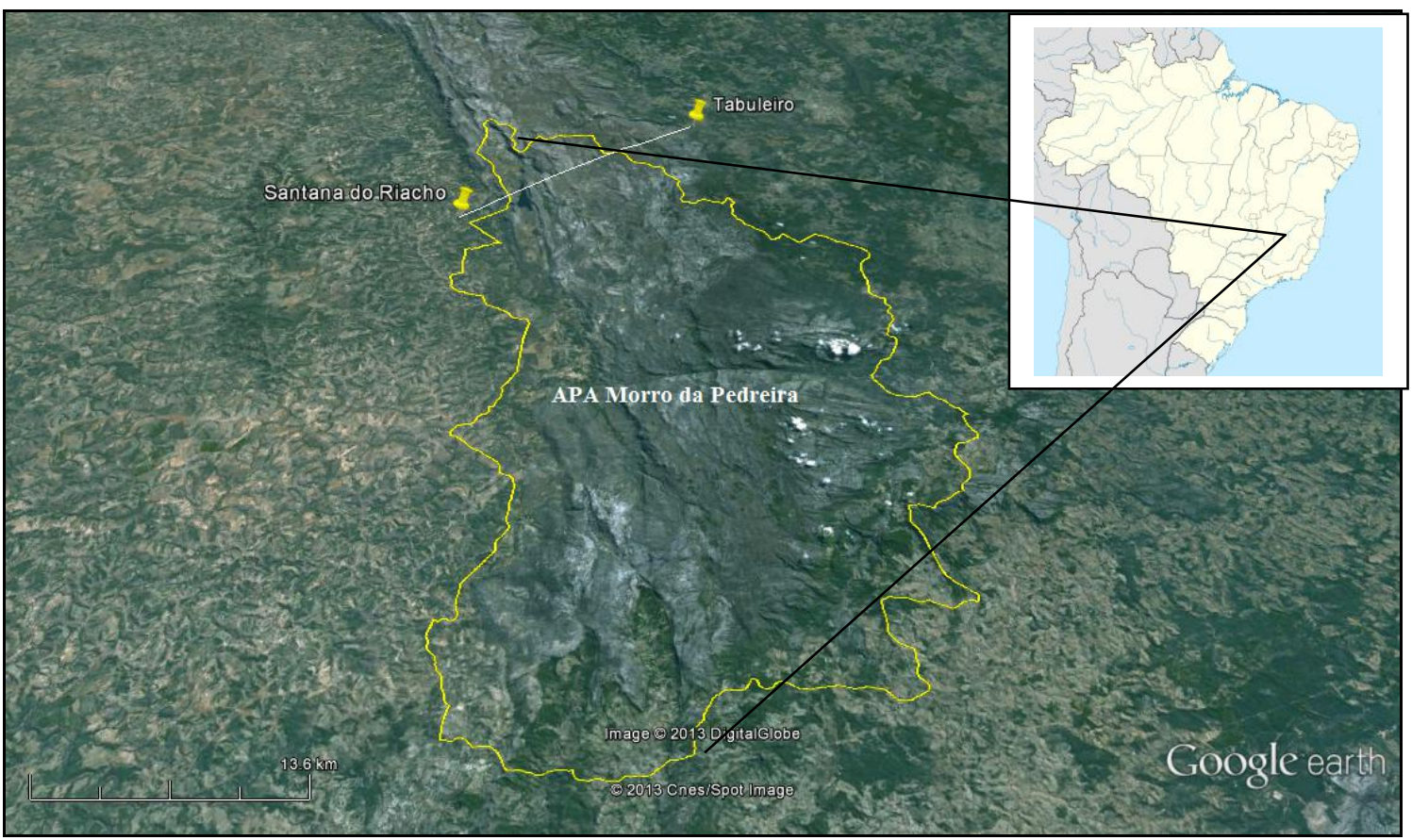

Fonte: Google Earth.

Ela distingue-se, principalmente, por sua singular heterogeneidade de ambientes perpassados ao longo de um cruzamento da Serra do Espinhaço, do sentido oeste para o leste. Tal variabilidade de paisagens não se restringe unicamente a espaços naturais. Quando falamos em heterogeneidade ambiental, nos referimos também ao espaço modificado e transformado pelo ser humano, assim como uma diversidade de valores, significados e simbologias por ele atribuídas a uma noção espaço e lugar.

O Espinhaço já se constitui por si só um vasto ambiente marcado pela variabilidade e pela diversidade, definido pelo seu alto grau de endemismo presente na serra em meio a um ambiente ecologicamente restritivo, além de abrigar dois importantes biomas brasileiros e extremamente ameaçados pelo contínuo avanço dos processos de urbanização: o Cerrado e a Mata Atlântica.

A serra já é conhecida e visitada por naturalistas há cerca de 300 anos e, segundo Gontijo (2008), Ludwig von Eschwege, um alemão e geólogo, a ela concedeu o nome de Espinhaço. Este nome faz uma referência a "espinha" que se segue de Minas até o estado baiano dividindo dois ambientes contrastantes, da borda leste coberta por vegetação característica de Mata Atlântica e da borda oeste constituída pela vegetação típica do Cerrado. 
Além da importância geoambiental, pode-se também citar as peculiaridades históricas referentes ao Espinhaço em meados do século XVIII, nas famosas expedições realizadas com a finalidade de explorar o território brasileiro. Lá encontra-se a pequena Vila de Lapinha, assim como o Tabuleiro, onde a principal finalidade era oferecer suporte aos tropeiros que faziam o percurso, antes mesmo da descoberta do diamante em regiões circundantes. Assim, temos o produto de uma paisagem que nos fornece indícios de uma história marcada pela busca incessante por ouro e pela escravidão em pleno Brasil colonial. Segundo Gontijo (2003), caracteriza-se por mais uma corrente migratória, acuando as populações indígenas da região e formando-se novos núcleos populacionais na região do entorno da Serra do Cipó, deflagrado, principalmente, pela descoberta do ouro em depósitos de aluvião.

Contempla-se também a importância arqueológica da região, atribuída principalmente ao naturalista dinamarquês Peter Wilhelm Lund, que percorreu cerca de 200 cavernas e grutas registrando e estudando a história de nossos antepassados. Corroborando com o valor histórico e arqueológico, temos também a missão franco-brasileira que escavou o sítio de Lapa Vermelha, encontrando inúmeros registros fosseis de seres humanos, inclusive o crânio batizado de Luzia, com idade aproximada de 11 mil anos.

Dessa forma, aponta-se a Serra do Espinhaço como região prioritária para a conservação em função de sua diversidade socioambiental, sendo que a travessia de Lapinha ao Tabuleiro é uma ferramenta potencial para conscientização e educação ambiental, além de promover a compreensão e vivência de novas formas de reprodução social.

\section{Materiais e Métodos}

Esse trabalho é resultado direto de um processo construtivo de seis meses de atividades, sendo elas divididas em três etapas: (i) preliminar, (ii) trabalho de campo, (iii) desenvolvimento e análise dos dados.

Na primeira etapa, de caráter preliminar, foi realizado um estudo do ambiente físico propriamente dito, a partir de um transecto entre Santana do Riacho a Tabuleiro, permitindose a elaboração de um croqui contendo o perfil altimétrico, as camadas geológicas e os tipos vegetacionais presentes na região. Foram mapeadas as unidades de conservação na região da Serra do Cipó e fez-se uma transposição da rota da travessia entre as localidades.

A segunda etapa consistiu num trabalho de campo na Serra do Cipó, realizando-se a travessia de Lapinha a Tabuleiro durante três dias, percorrendo-se cerca de 40 quilômetros. As atividades de campo foram essenciais para a coleta de dados e verificação das informações obtidas na primeira etapa. Um total de 90 pontos, registrados com ajuda de um GPS, permitiram a reconstrução da rota e identificação de pontos importantes, além das anotações diárias das atividades em uma caderneta de campo, juntamente a um registro fotográfico completo do caminho.

No terceiro e último momento, realizou-se a análise dos dados obtidos em campo, além de levantarmos de novas informações relevantes ao estudo como, por exemplo, a estrutura demográfica e alguns indicadores socioeconômicos. 


\section{Resultados}

a) Roteiro

A travessia realizada numa caminhada de cerca de 40 quilômetros, desenvolveu-se em três dias no tradicional percurso de Lapinha a Tabuleiro (como indicado na Figura 2). $\mathrm{O}$ mesmo foi realizado com a assistência de um GPS, auxiliando na marcação de pontos para posterior identificação da trilha completa na imagem de satélite.

Figura 2. Reprodução do trecho percorrido através dos pontos coletados via GPS.

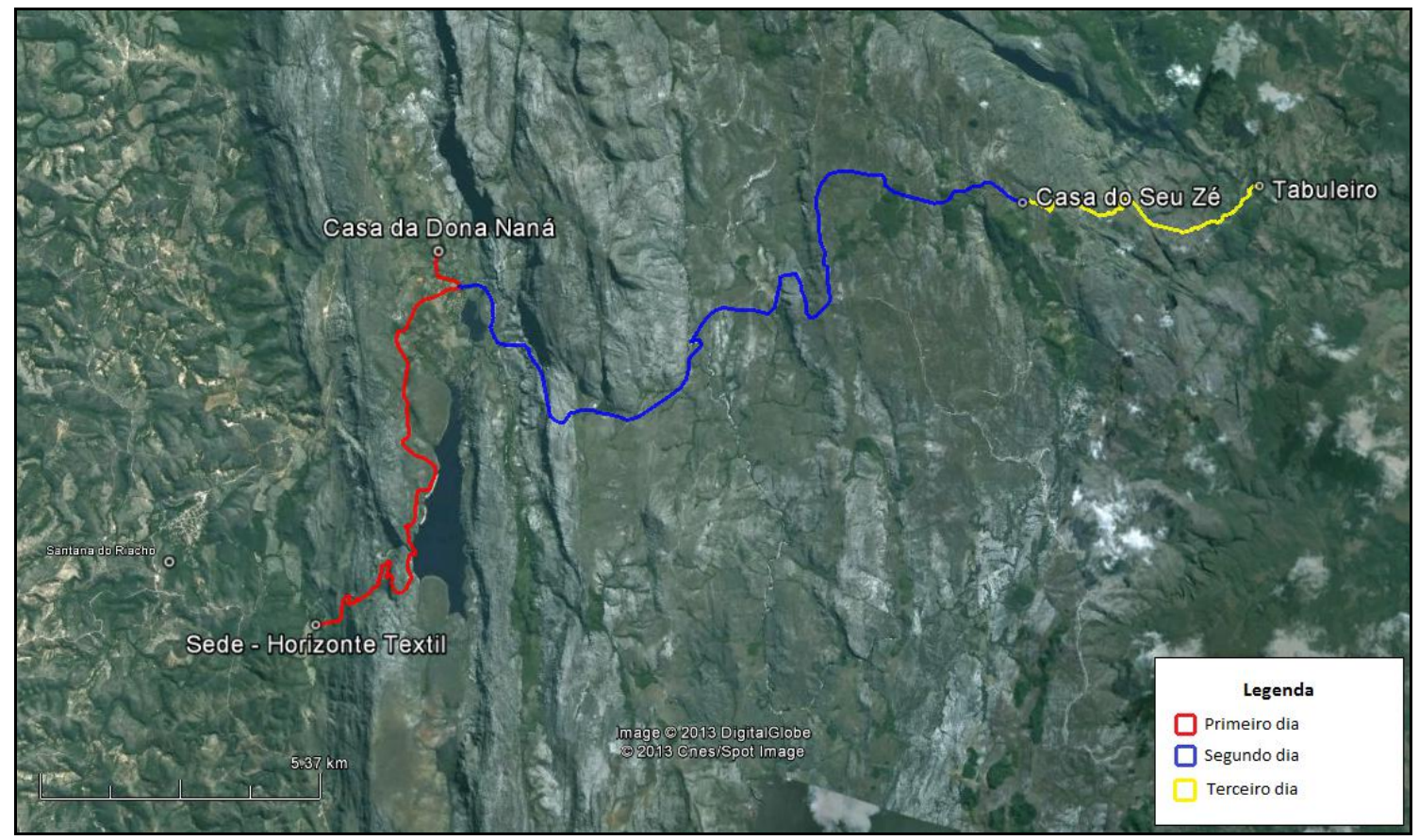

Desse modo, reconstituiu-se a viagem subdividida a cada dia de caminhada, sendo o primeiro demarcado em vermelho, o segundo em azul e o terceiro em amarelo. Foi identificado na imagem pontos de interesse principais: a sede da Horizonte Textil ${ }^{2}$ (localizada próximo a Santana do Riacho), que marca o início da caminhada; a casa da Dona Naná (Lapinha da Serra), onde pernoitamos no primeiro dia; a casa do seu Zé, onde dormimos no segundo dia; e no terceiro, finalizando a viagem em Tabuleiro.

b) Formações vegetais

Realizou-se a identificação e descrição de todas as formações vegetacionais existentes na região ao longo da travessia. Para tanto utilizamos um mapa de uso do solo proveniente do Zoneamento Ecológico-Econômico do Estado de Minas Gerais ${ }^{3}$, ferramenta decorrente da elaboração de um diagnóstico geo-biofísico e socioeconômico, gerando mapas representativos e diversas possibilidades de análises. Dessa forma, o trabalho preliminar desenvolvido e a

\footnotetext{
${ }^{2}$ Empresa responsável pela Usina Hidrelétrica Coronel Américo Teixeira.

${ }^{3}$ Disponível em: <http://www.zee.mg.gov.br/>
} 
verificação em campo resultaram em quatro formações distintas segundo o Manual Técnico da Vegetação Brasileira (IBGE, 2012), sendo elas: cerrado, campo rupestre, campo de altitude e floresta estacional semidecidual.

O termo Cerrado se origina na Espanha, o qual atribui o significado de "fechado". Muito conhecido também como a savana brasileira, o Cerrado pode ser considerado, hoje, a segunda maior formação vegetal do Brasil, ocupando cerca de $25 \%$ do território nacional. Segundo Rizzini (1979), esse complexo vegetacional é caracterizado por cinco graus de densidade e altura dos indivíduos, no entanto, é marcado por um solo profundo e chuvas regulares de outubro a março, com pluviosidade média de $1.300 \mathrm{~mm}$. O substrato é muito permeável, permitindo assim a percolação da água no solo.

Os campos rupestres constituem ecoregiões que se situam nas proximidades da Mata Atlânticas e Cerrados, sendo consideradas unidades florísticas que constituem uma grande heterogeneidade de habitats, o qual pode estar associado a diversos fatores ambientais (MESSIAS, 2012). É importante ressaltar também que em função da grande heterogeneidade da paisagem, nota-se uma enorme diversidade florística entre campos rupestres distintos, em outras palavras, observa-se uma grande diversidade alfa $^{4}$ e diversidade beta ${ }^{5}$ (JACOBI, 2008).

Rizzini (1979) afunila a definição de campos rupestres quartzíticos em três categorias: (i) campo quartzítico com gramíneas, (ii) campo quartzítico com gramíneas e subarbustos e (iii) campo quartzítico dos afloramentos. Os campos rupestres, em síntese, ocorrem principalmente em altitudes acima de 900 metros, característicos de montanhas cuja formação das rochas é de origem pré-cambriana, se associando, principalmente aos afloramentos de quartzito, arenito e minério de ferro (VASCONCELOS, 2011).

Já os campos de altitude podem ser considerados uma unidade florística que ocorre em pontos mais elevados de montanhas soerguidas no Terciário, possuindo altitude superior a 1.500 metros, estando comumente associados a rochas de caráter ígnea ou metamórfica como, por exemplo, granito ou gnaisse (VASCONCELOS, 2011). Rizzini (1979) define essa ecorregião como campo altimontano, caracterizado pela vegetação campestre xerófila adaptada a uma estação de seca no meio do ano e ao solo raso, além de estar exposta à radiação solar intensa em função da altitude. Por fim, apesar das semelhanças visuais notáveis entre campos rupestres quartzíticos e campos de altitude, vários levantamentos florísticos identificaram diferenças em sua composição (RIZZINI, 1979).

A floresta estacional semidecidual ou mata mesófila, categoria intimamente ligada ao conjunto da Mata Atlântica, é caracterizada pelo seu comportamento distinto diante a duas estações climáticas. Uma estação de chuvas intensas no verão e um período de estiagem, que é quando cerca de $20 \%$ a $50 \%$ das árvores perdem suas folhagens. Esse fenômeno é atribuído a espécies caducifólias, caducas ou decíduas a fim manter a água retida no organismo e não perdê-la na evapotranspiração através das folhas.

\footnotetext{
${ }^{4}$ Variabilidade a nível local.

${ }^{5}$ Complementariedade entre fragmentos, habitats ou região.
} 
A partir do Manual Técnico da Vegetação Brasileira (IBGE, 2012), o tipo vegetacional da floresta estacional semidecidual foi delimitado em quatro formações diferentes: (i) Floresta Estacional Semidecidual Aluvial, (ii) Floresta Estacional Semidecidual das Terras Baixas, (iii) Floresta Estacional Semidecidual Submontana e (iv) Floresta Estacional Semidecidual Montana. As quatro formações vegetacionais descritas podem ser identificadas durante o percurso proposto, variando principalmente em função da altitude, colocando-nos em contato com a heterogeneidade de paisagens anteriormente citada.

c) Geologia local

No contexto do estudo em questão, pode-se dividir geologia em dois momentos: 1) Análise do Grupo Bambuí, o qual envolve Santana do Riacho e a porção de Lapinha e análise do Grupo Macaúbas, que abrange o entorno de Lapinha da Serra; 2) Análise do Supergrupo Espinhaço, que contem a região de Conceição do Mato Dentro, Tabuleiro e proximidades.

O Grupo Bambuí, formado no período proterozóico, inclui a (i) Formação Lagoa do Jacaré; (ii) Formação Serra de Santa Helena e (iii) Formação Sete Lagoas. O grupo Macaúbas, também formou-se no período proterozóico.

$\mathrm{Na}$ área representada pelo Grupo Bambuí, vemos a predominância de rochas e sedimentos carbonáticos como por exemplo o calcário e o dolomito, existindo a possibilidade de ocorrência local de estromatólitos (Serviço Geológico do Brasil, 2012).

Vemos que a geologia na região da represa da usina hidrelétrica Coronel Américo Teixeira é formada basicamente por calcário metamorfizado e bandado e seu entorno é formado por quartzitos de uma mesma formação geológica, fato este que pode estar relacionado à regressão marítima, que com a deposição de matéria orgânica e precipitação de carbonato de cálcio no ambiente possibilitou reações químicas que originasse a formação calcária.

Já o Supergrupo Espinhaço, formado no mesoproterozóico, engloba a (i) Formação Córrego Borges; (ii) Formação Santa Rita; (iii) Formação Galho do Miguel e (iv) Formação Sopa Brumadinho.

Ao analisar as formações que compõem o Supergrupo Espinhaço, vemos que em grande parte são compostas por quartzitos de granulação variada, o que implica na ocorrência de solos com um caráter mais arenoso, mais rasos e pobres em nutrientes, mais secos em decorrência da sua disfunção em reter a umidade, justificando assim, a grande ocorrência de campos rupestres. 
d) Travessia Lapinha $x$ Tabuleiro

A travessia teve como marco inicial a sede da empresa Horizonte Têxtil responsável pela usina hidrelétrica Coronel Américo Teixeira, localizada entre Santana do Riacho e o vilarejo de Lapinha da Serra, nosso destino no primeiro dia de caminhada.

Num total de 12 quilômetros percorridos no primeiro dia, observou-se a influência da altitude como fator intrínseco da composição florística de uma formação vegetacional, uma vez que partimos de uma elevação média de $700 \mathrm{~m}$ e atingimos cerca de $1.200 \mathrm{~m}$ de altitude, o que implica em diferentes ambientes em função das distintas dinâmicas ambientais em cada valor altimétrico.

No ponto de partida foi possível registrar uma vegetação característica de Cerrado (figura 3), enquanto a medida que subíamos foi perceptível um declínio acentuado do porte e da quantidade de indivíduos.

Figura 3. Vegetação característica de cerrado.

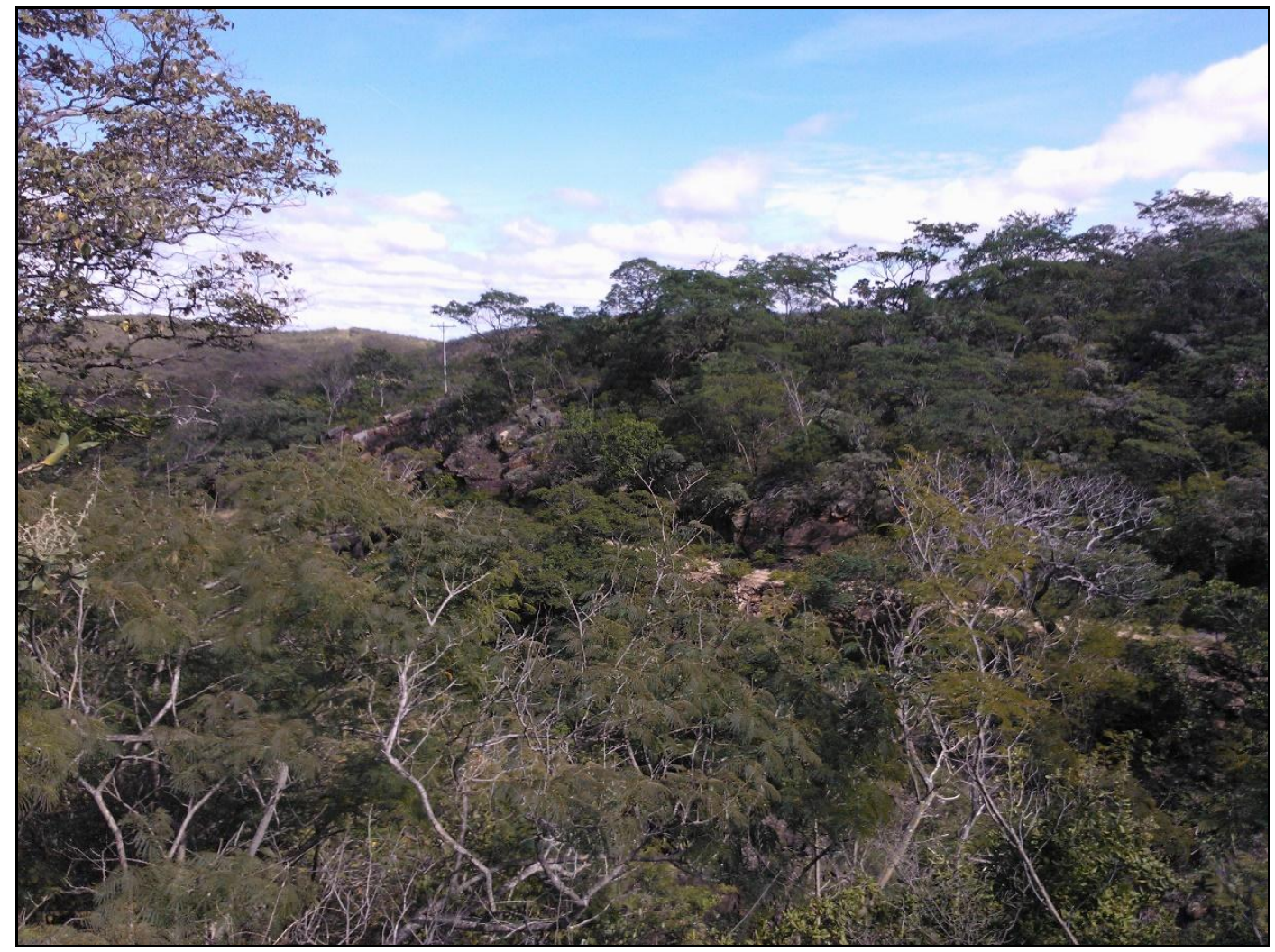

Atingindo uma elevação de 1.000 metros, o Cerrado começa a dar lugar a campos rupestres quartzíticos, onde é facilmente observável a transição das unidades florísticas (figura 4), principalmente com o surgimento de espécies características, como por exemplo da família velloziaceae, que começam a se espalhar pela paisagem (figuras 5 e 6). 
Figura 4. Transição de Cerrado para campo rupestre.

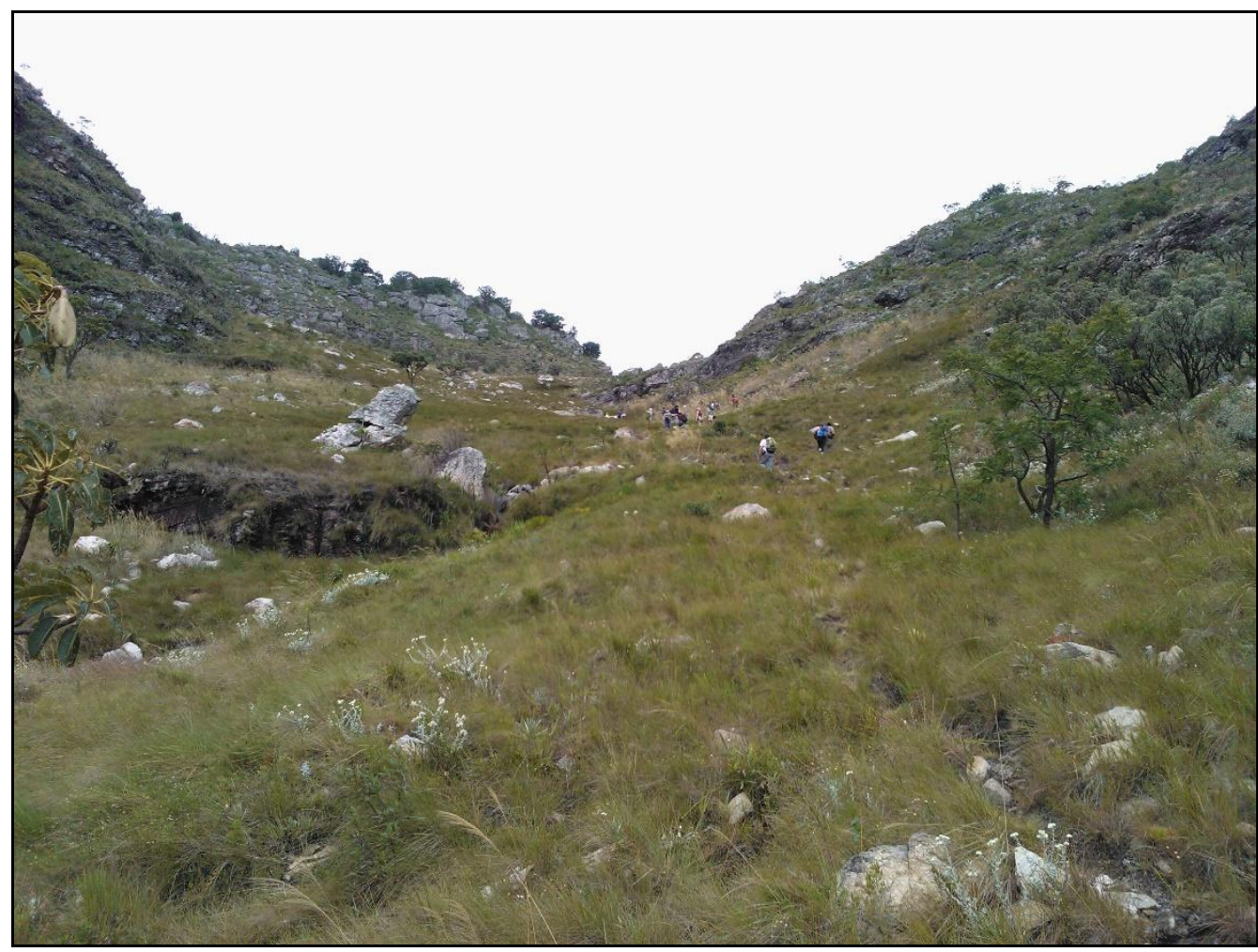

Figura 5. Velloziaceae.

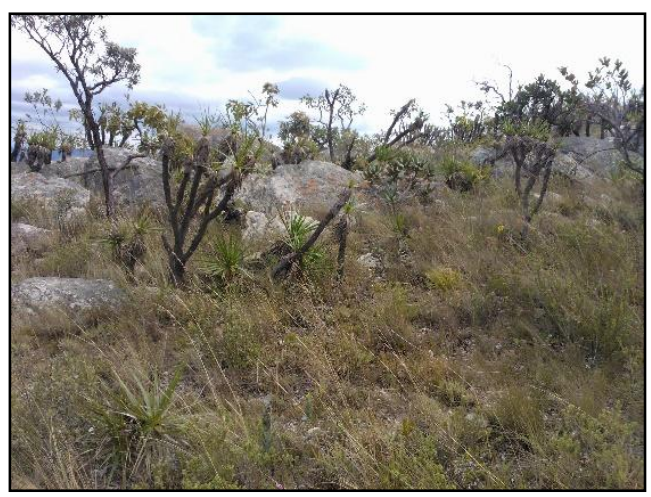

Figura 6. Velloziaceae.

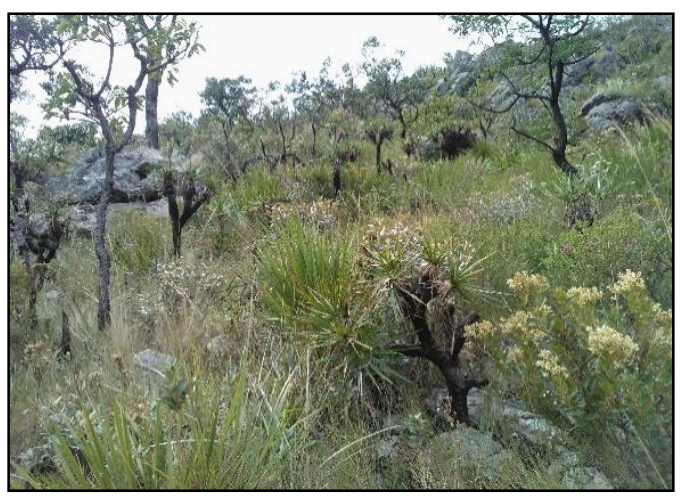

Essa diferenciação da vegetação em função da altitude pode ser percebida ao longo de todo o percurso da travessia, fato também verificado e analisado pelo naturalista francês Saint-Hilaire ao observar a diversidade de fatores ecológicos que promoveram condições e/ou restrições no ambiente.

Não se julgue que as matas virgens sejam por toda a parte absolutamente idênticas; apresentam variações conforme a natureza do terreno, a elevação do solo e a distância do equador. As matas dos arredores do Rio de Janeiro têm mais majestade do que em todas as que vi em outras partes do Brasil, talvez porque em parte alguma a umidade seja tão grande como lá; entretanto, as florestas das províncias do Espirito Santo e Minas Gerais, 
mesmo as das províncias mais meridionais de São Paulo e Santa Catarina, têm também suas belezas(...) (SAINT-HILAIRE, apud NOGUEIRA, 2005).

Corroborando com a ideia de que o Espinhaço apresenta uma singular heterogeneidade de paisagens, vemos no gráfico representativo do perfil altimétrico da travessia (figura 7) a oscilação da elevação, sendo o mesmo subdividido nos três dias da caminhada.

Figura 5. Perfil altimétrico da travessia Lapinha x Tabuleiro.

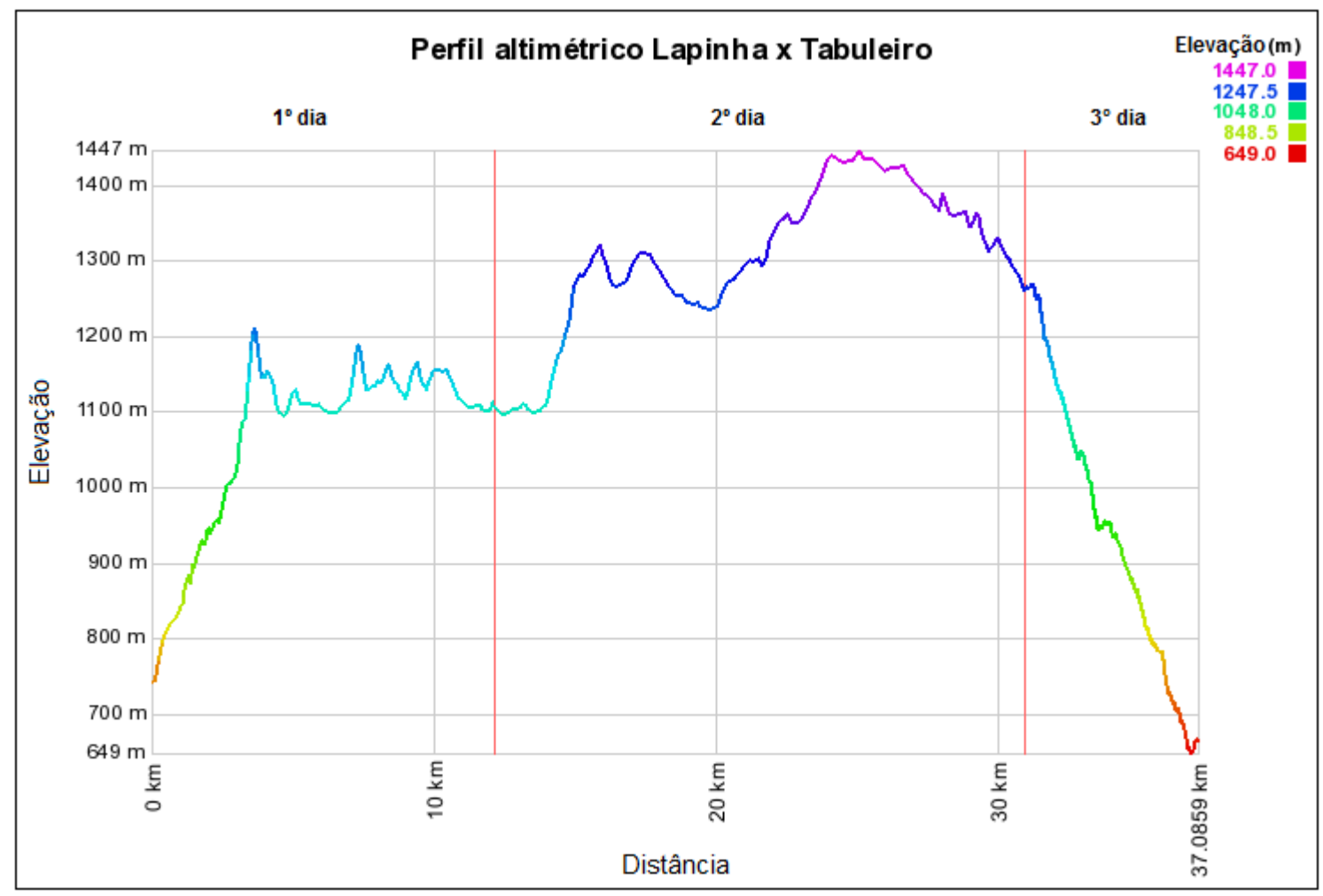

Essa variação da altimetria pode ser usada como referência para estabelecer diferenças na composição da vegetação, uma vez que a altitude pode ser definida como um dos principais fatores ecológicos determinantes da flora, visto que a elevação também pode ser relacionada com diversos outros fatores, como por exemplo a umidade relativa, o tipo de solo e disponibilidade hídrica.

É interessante ressaltar que no segundo dia de caminhada passamos por três unidades paisagísticas completamente distintas: campos rupestres situados entre 1.200 e $1.300 \mathrm{~m}$, campos de altitude próximos aos $1.450 \mathrm{~m}$ e pastagens inseridas dentre diversas propriedades privadas que foram atravessadas (figura 8).

No terceiro dia confirmou-se a relação entre elevação e vegetação, visto que temos uma variação de $1.300 \mathrm{~m}$ na partida, até $650 \mathrm{~m}$ no ponto final da travessia, já em Tabuleiro. No caminho percorrido é facilmente perceptível o aumento do porte arbóreo e da densidade da vegetação com o constante declínio da elevação, assim como mudanças drásticas no microclima. 
Figura 6. Campos de altitude (1.400 metros).

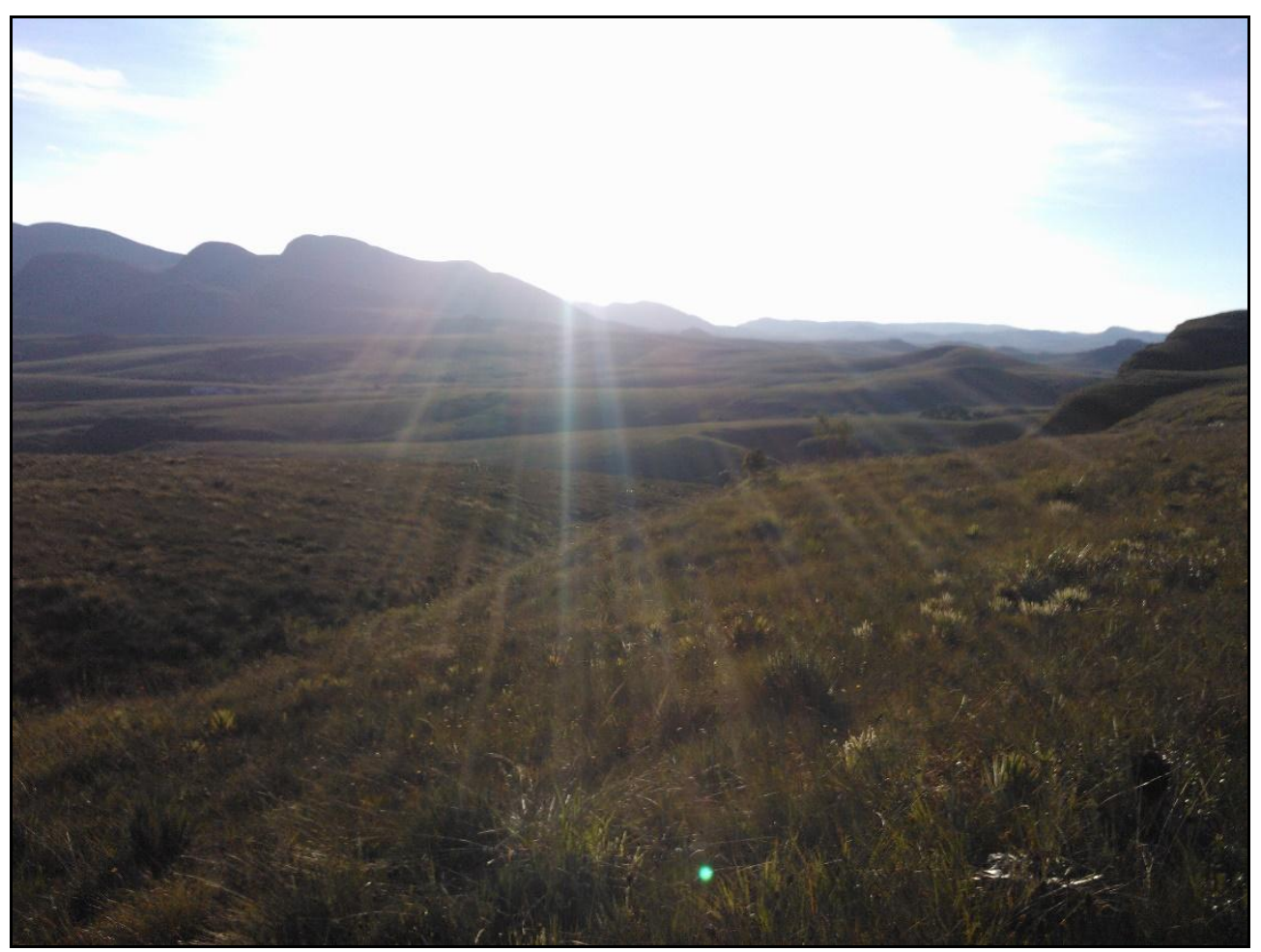

No ponto mais alto da travessia registrado pelo GPS (1.447 metros de altitude) identificamos claramente o divisor de águas entre duas bacias hidrográficas: Bacia do Rio São Francisco e Bacia do Rio Doce, onde a vegetação define o contraste entre ambas.

Figura 7. Identificação das bacias na paisagem.

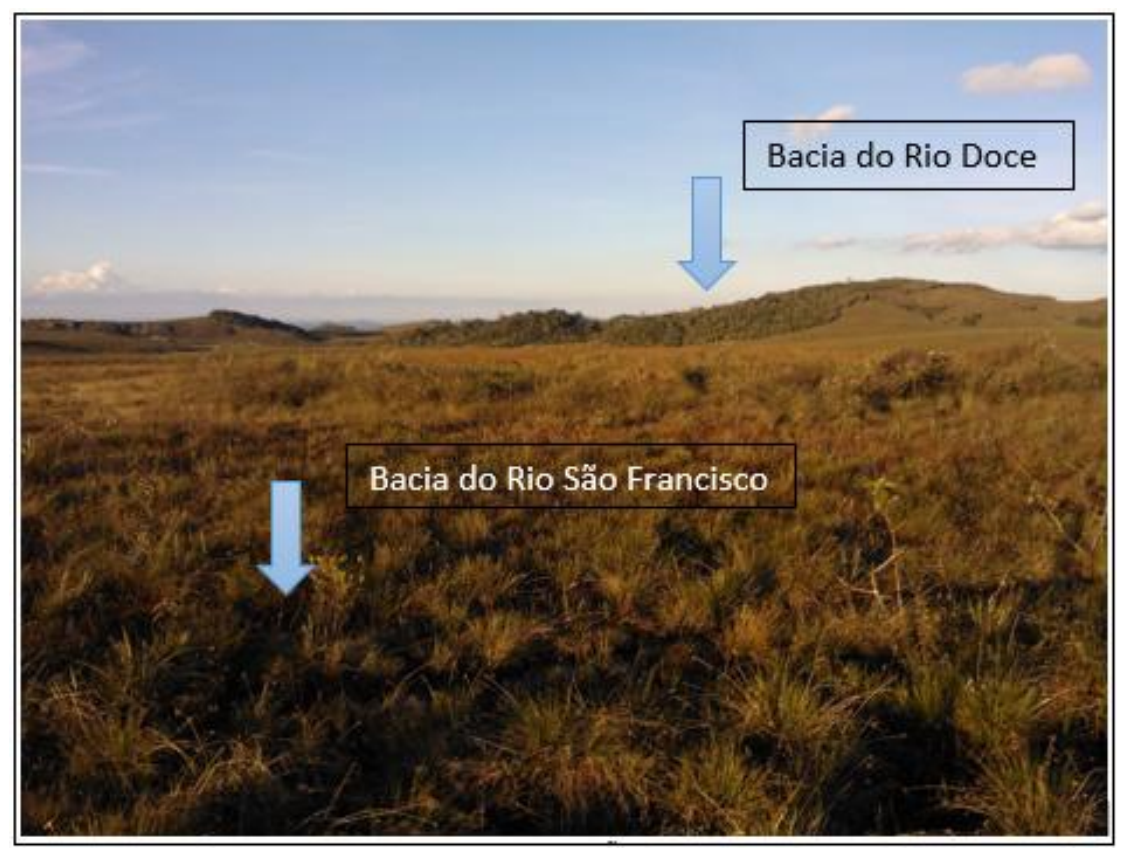


Na borda identificada como parte da bacia do Rio São Francisco há predomínio da vegetação característica do Cerrado. Em contrapartida, na bacia do Rio Doce, prevalece a vegetação característica de Mata Atlântica (ou apenas fragmentos).

A vegetação, de maneira geral, pode ser considerada um fator de formação do solo, embora o tipo de solo seja um fator ecológico determinante na composição florística. Rizzini (1979) aponta a interação da rocha-mãe (ou rocha-matriz), da vegetação e da ação do clima como vetores resultantes do solo, como identificado na figura 9.

Figura 8. Processos de formação dos solos. Adaptado de Rizzini (1979).

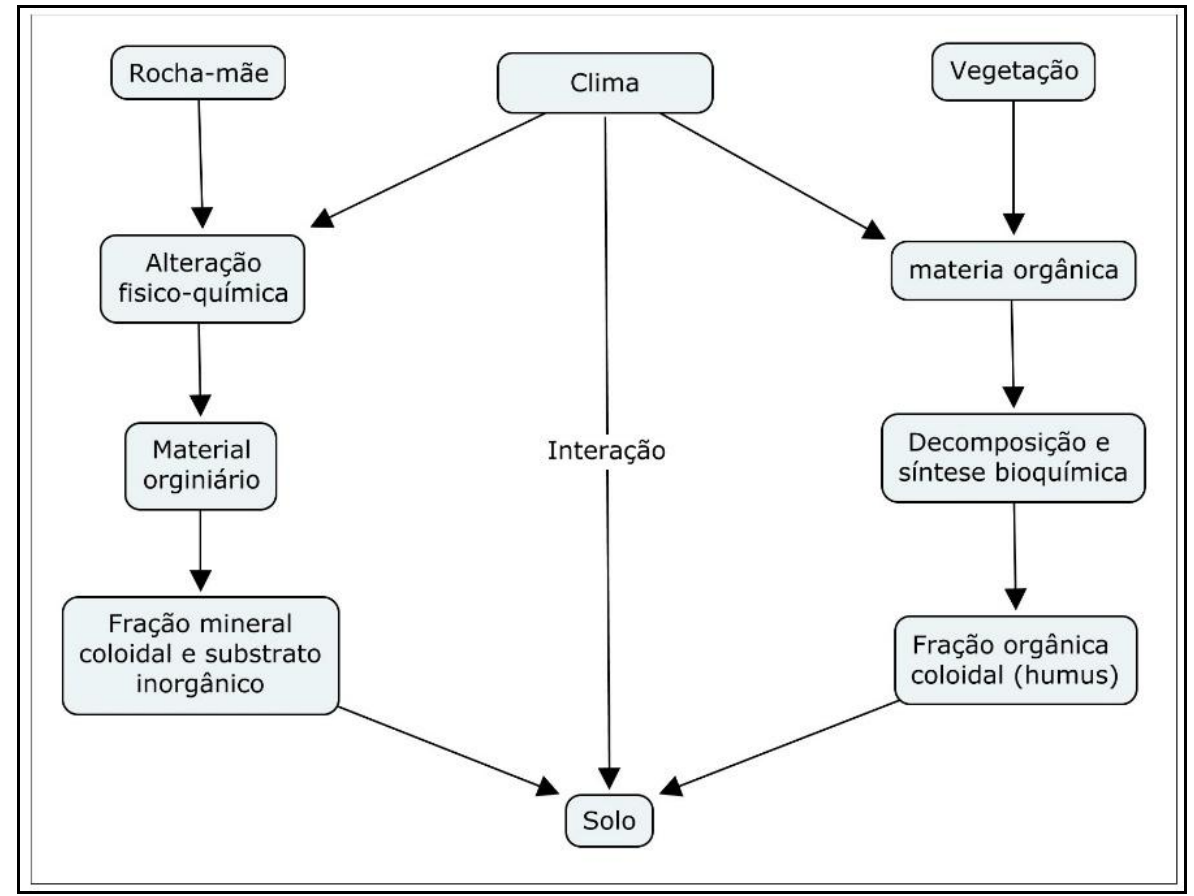

Em função da rocha-matriz ser constituída por quartzito em grande parte da travessia, predominam os solos mais jovens caracterizados por campos rupestres, principalmente nas localidades mais elevadas onde a vegetação é mais escassa e a ação do intemperismo é mais branda. São encontradas regiões no Supergrupo do Espinhaço em que predominam filitos que, por apresentarem um caráter mais argiloso, em épocas de chuva se tornam extremamente encharcados. Na estiagem tornam-se secos e compactos, contudo, por serem argilosos acabam concentrando mais água e retendo nutrientes sendo, portanto, um tipo de solo mais indicado para a prática da agricultura.

Dessa forma, começamos a compreender como a relação dos elementos fisiográficos produzem um mosaico de escolhas que permeiam a população local e constituem seu modo de vida, muitas vezes, distante de uma lógica capitalista vividas por nós em grandes centros urbanos. Tem-se uma visão completamente distinta do Espinhaço e pode-se criar um vínculo completamente diferenciado do elo que enraíza a população de Lapinha e de Tabuleiro.

Durante a travessia fomos acolhidos por duas famílias residentes da região, no primeiro dia na casa de Dona Naná, no vilarejo de Lapinha, onde vive com sua família em 
uma casa famosa pelos pratos saborosos. Já no segundo dia fomos recebidos na casa de Seu Zé e sua família, próximo à Tabuleiro, o qual a simplicidade e a humildade são sinônimos de sua personalidade. Pode-se dizer que ambas as famílias são tradicionais da região, guardando fascinantes histórias e experiências que muitos de nós jamais vivenciaremos, distante de nossas realidades, contudo, rica em ínfimos detalhes e repletos de alegria.

É no contraste a um modelo de vida urbano e dinâmico que colocamos a casa de Seu Zé e Dona Naná, inseridas em uma atmosfera extremamente carregada de vida, onde pode ser vivenciada em uma travessia de três dias, com 40 quilômetros de extensão e uma infinidade de experiências em meio ao ambiente natural da Serra do Espinhaço.

\section{Considerações finais}

O estudo mostra a importância didática do ponto de vista da educação ambiental da travessia Lapinha x Tabuleiro, posto que é possível observar com nitidez os fatores ecológicos responsáveis pela conformação das formações vegetais. Colocamos a variação da altimetria como um condicionante ambiental, visto que o mesmo é responsável por acentuar dinâmicas ambientais e processos ecossistêmicos.

A travessia Lapinha $\mathrm{x}$ Tabuleiro acaba operando como uma ferramenta aliada da conservação da biodiversidade, uma vez que a heterogeneidade de paisagens se faz imprescindível para a sustentação da diversidade biológica. É preciso preservar não só o ambiente físico concebido a partir das interações das dinâmicas ambientais, se faz necessário resguardar a manutenção das relações socioambientais idealizados no espaço pela população local, que guarda marcas e memórias do Espinhaço desde o período do Brasil Colonial.

Dessa forma, devemos perceber o uso de travessias e trilhas como um modo de sensibilizar e promover a mudança de hábitos, representando assim um importante instrumento pedagógico e educativo, uma vez que apresenta um grande potencial para introduzir e/ou induzir o visitante a crítica da relação homem-natureza, constituindo, portanto, em um importante passo para conservação ambiental.

Desse modo, é preciso lembrar da frágil questão relacionada as áreas protegidas em território brasileiro, onde se faz notório a pressão do capital sobre nossas unidades de conservação que tentam, acima de tudo, garantir a proteção da nossa biodiversidade.

Temos, por fim, uma região rica de histórias e de tesouros ambientais que necessitam de proteção e, infelizmente, as unidades de conservação hoje existentes não conseguem abarcar todo o Espinhaço, o que acaba se tornando uma fragilidade do ponto de vista político, já que o avanço do vetor norte, da indústria do turismo e a chegada da urbanização constituem uma oferta tentadora do nosso sistema capitalista que faz com que, no final das contas, tenhamos que nos defender de nós mesmos. 


\section{Referências bibliográficas}

CODEMIG. Projeto Espinhaço. Companhia de Desenvolvimento Econômico de Minas Gerais: s/d. Disponível em: <http://www.codemig.com.br/site/content/parcerias/levantamento_aerogeofisico.asp?id=30\&i $\mathrm{dSubPrj}=50 \&$ filhoId=51> Acesso em: 02/06/2013.

COSTA, F. Medindo a diversidade. La Insignia. Editora Independente: UnB, 2007.

CPRM. Rochas Carbonáticas do Grupo Bambuí. Disponível em: < http://www.cprm.gov.br/publique/cgi/cgilua.exe/sys/start.htm?infoid=261\&sid=32> Acesso em: 02/06/2013.

GONTIJO, Bernardo. Uma geografia para a Cadeia do Espinhaço. Megabiodiversdade Cadeia do Espinhaço: avaliação do conhecimento científico e prioridades de conservação volume 4, $\mathrm{N}^{\circ}$ 1-2, Dezembro 2008. pp. 7-15

GONTIJO, Bernardo. A Ilusão do ecoturismo na Serra do Cipó MG, o caso de Lapinha. Abril de 2003. 210 f. Tese (Doutorado em Desenvolvimento Sustentável) - Universidade de Brasília. Brasília, DF, 29 de abril de 2003.

IBGE. Manual Técnico da Vegetação Brasileira. Rio de Janeiro: Instituto Brasileiro de Geografia e Estatística, 2012. 271 f., $1^{\circ}$ edição.

JACOBI, C. M. e CARMO, F. F. Diversidade dos Campos rupestres ferruginosos no Quadrilátero Ferrífero, MG. Departamento de Biologia Geral, Universidade Federal de Minas Gerais. Revista Megadiversidade, v. 4, n.1-2, Belo Horizonte, dezembro de 2008.

JACOBI, C.; CARMO, F. F. e VINCENT, R. C. Estudo fitossiológico de uma comunidade vegetal sobre canga como subsídio para a reabilitação de áeas mineradas no Quadrilátero Ferrífero, MG. Sociedade de Investigadores Florestais, v. 32, n. 2, p. 345353, Viçosa, 2008. Disponível em: 〈http://www.scielo.br/pdf/rarv/v32n2/a17v32n2.pdf>.

PORTAL DA SERRA. Lapinha da Serra. Disponível em: < http://www.portaldalapinha.com.br/lapinhadaserra.php> Acesso em: 02/06/2013.

MESSIAS, M. C. T. B. et al. Fitossociologia de campos rupestres quartzíticos e ferruginosos no Quadrilátero Ferrífero, Minas Gerais. Acta Bot. Bras., v. 26, n. 1, Feira de Santana, março de 2012.

NOGUEIRA, M. M. Os caminhos do Ouro e o registro da vegetação segundo Naturalistas do Século XIX. In: COSTA, A, G. (org). Os Caminhos do Ouro e a Estrada Real. Belo Horizonte: Editora da UFMG; Lisboa: Kapa Editorial, 2005.p. 152-191.

PADOAN, Lucas. Relatório de Campo. Trabalho de conclusão da disciplina Fitogeografia. Universidade Federal de Minas Gerais. Belo Horizonte, 2013.

PNUD. Atlas do Desenvolvimento Humano do Brasil 2013. Disponível em: < http://atlasbrasil.org.br/2013/consulta> Acesso em: 14/10/2013. 
RIZZINI, Carlos. (1979). Tratado de Fitogeografia do Brasil: aspectos sociológicos e florísticos. São Paulo: HUCITEC - EDUSP, 1979. 374 p., $2^{\circ}$ volume.

VASCONCELOS, Marcelo Ferreira de. O que são campos rupestres e campos de altitude nos topos de montanha do leste do Brasil?. Rev. bras. Bot. [online]. 2011, vol.34, n.2, pp. 241-246. ISSN 0100-8404 